ORIGINAL ARTICLE

\title{
Trichomonas vaginalis IN FEMALE PRISON INMATES \\ FROM UBERLÂNDIA, MINAS GERAIS, BRAZIL: \\ PREVALENCE, DIAGNOSIS AND \\ EPIDEMIOLOGICAL ASPECTS
}

Natália Melo Nasser Fava ${ }^{1}$, João da Costa Viana ${ }^{2}$ and Márcia Cristina Cury ${ }^{1}$

\section{ABSTRACT}

Trichomonas vaginalis is the etiological agent of trichomoniasis one of the most prevalent sexually transmitted infections worldwide. This paper aimed to determine the prevalence and the risk factors associated to the dissemination of the parasite in the prison environment, as well as comparing the diagnostic methods used for its detection. The present study included 56 female inmates at Professor Jacy de Assis Penitentiary, in Uberlandia, Minas Gerais, Brazil, regardless of ethnicity, socioeconomic status, age and sexual orientation. To diagnose $T$. vaginalis, wet mount and culture in TYM medium were utilized. The results were compared to the Papanicolaou test, the routine diagnostic method used in prisons. To outline the socioepidemiological profile of the participants an investigative survey was applied during an interview preceding the medical consultation. Of the 56 women included in the present study, six were diagnosed positive for $T$. vaginalis, by the three methods resulting in a prevalence of $10.7 \%$. Culture and wet mount presented $100 \%$ specificity and sensitivity. On the other hand, sensitivity and specificity of the Papanicolaou test were $75 \%$ and $96 \%$, respectively. None of the variables analysed, herein, could be associated with the infection. Despite the presence of the parasite, it was not possible to set an epidemiological pattern for positive patients, highlighting the particularities of this population. Regarding the diagnostic methods, wet mount and culture were equally efficient and superior to Papanicolaou in detecting T. vaginalis.

KEY WORDS: Trichomoniasis; penitentiary; diagnosis; women; risk factors.

\section{INTRODUCTION}

Sexually transmitted infections (STIs) are an important public health problem that disproportionately affects incarcerated women when compared to the female population in general (CDC, 2006).

\footnotetext{
1. Laboratory of Serology and Molecular Biology of Parasites, Biomedical Science Institute, Federal University of Uberlândia (UFU), Av. Amazonas s/n, Campus Umuarama, Uberlândia CEP 38400-902, Minas Gerais, Brazil.

2. Parasitology Department, Biological Science Institute, Federal University of Minas Gerais, Belo Horizonte, Minas Gerais, Brazil.
}

Corresponding author: Natália de Melo Nasser Fava. Laboratory of Parasitology and Molecular Biology of Parasites, Biomedical Science Institute, Federal University of Uberlândia (UFU), Av. Amazonas s/n, Campus Umuarama, Uberlândia CEP 38400-902, Minas Gerais, Brazil. E-mail: natalia.nasser@yahoo.com.br 
In Brazil, women represent $6.4 \%$ of the prison population, being the fourth largest in the world (Brazil, 2018). Globally, this group tends to be young, presenting low socioeconomic and educational levels, a history of prostitution as well as alcohol and illicit drug abuse (Davis et al., 2018; Vlahov et al., 1989). These characteristics compose a population difficult to identify, address and treat in their own communities.

Trichomoniasis, caused by Trichomonas vaginalis, is the most common sexually transmitted infection of non-viral origin (Kissinger et al., 2015) with more than 156 million new cases annually, $90 \%$ of which occurring among people living in resource-limited settings (Rowley et al., 2019; WHO 2018).

According to the World Health Organization (WHO, 2016) 50\% of infections are asymptomatic, highlighting the importance of laboratory diagnosis for $T$. vaginalis control. Due to this asymptomatic pattern, clinical examination for trichomoniasis is not a reliable diagnostic method (Hardick et al., 2006). The nucleic acid amplification test (NAAT) has been the gold standard method for diagnosing T. vaginalis since 2015 (Workowski \& Bolan, 2015). However, due to its high costs, wet mount and culture are commonly used for detecting this parasite in research laboratories (Adjei et al., 2019).

Fresh microscopic examination presents a number of advantages such as speed, ease performance, low cost and immediate results (Bachmann et al., 2011). However, sensitivity is low, varying from $50 \%$ to $80 \%$ when compared to culture (Soper, 2004). In addition to providing reliable results the culture method also presents other advantages, such as the small amount of inoculum to start the growth (300 to 500 T. vaginalis $/ \mathrm{mL}$ ) low cost and the ease in viewing and interpreting results (Bachmann et al., 2011),

In health services, especially public services, Papanicolaou is the most utilized method, since it includes screening for various cytological abnormalities. However, Perl (1972) reported an error rate of $48.4 \%$ due to false negative and false positive results when this method was the only one used for diagnosis. Colouring techniques are limited, since the parasite does not appear in the typical pyramidal shape with flagella, but round similar to leukocytes (Michel et al., 2006).

T. vaginalis is an important source of reproductive morbidity and may amplify the acquisition and transmission of other STIs such as Acquired Immunodeficiency Syndrome (AIDS). It has also been associated with poor birth outcomes such as low birth weight, preterm delivery, pelvic inflammatory disease, and premature rupture of membranes (Silver et al., 2014). Nevertheless, information on the exact prevalence of the infection is scarce, since it is not currently a notifiable disease (Poole \& McClelland, 2013) and public health services give it limited attention (Van Der Pol, 2007). 
This study, therefore, aimed to determine the prevalence of $T$. vaginalis in inmates, to identify the risk factors of the disease and to associate them with infection, besides evaluating the effectiveness of the three diagnostic methods proposed herein (culture, wet mount and Papanicolaou).

\section{METHODS}

\section{Study population}

This epidemiological study to diagnose $T$. vaginalis, was carried out between May 2010 and November 2010 in the Jacy de Assis Penitentiary, in Uberlândia, Minas Gerais, Brazil, with 56 female inmates, over 18 years of age, who agreed to participate regardless of ethnicity, origin, sexual orientation, socioeconomic and cultural characteristics and time of incarceration. To ratify participation, the volunteers signed a free and informed consent form containing all information about the study and the research group responsible for it.

The penitentiary houses prisoners from Uberlândia and adjacent areas who are awaiting trial or have already been sentenced to up to eight years incarceration. There are 11 pavilions, one of which is for female inmates, housing 80 women on average.

Due to the sexual route of transmission of $T$. vaginalis, it was decided that women who had not yet taken up sexual activity would be excluded from the study. All other women would participate in the study, regardless of any other criteria.

\section{Sampling}

Vaginal samples were collected by the gynaecologist using a swab of non-absorbent cotton and with the aid of a speculum. Two samples were collected from each woman, one from the vaginal pool which was stored in a screw-capped $15 \mathrm{~mL}$ tube, containing $1 \mathrm{~mL}$ of $2 \%$ warm glycosylated isotonic saline for the wet mount method, and one from the vaginal wall, stored in a tube containing trypticase-yeast extract-maltose (TYM) culture medium (Diamond, 1957) supplemented with 10\% bovine serum, $1000 \mathrm{IU} /$ $\mathrm{mL}$ penicillin and $1 \mathrm{mg} / \mathrm{mL}$ streptomycin sulphate at $\mathrm{pH} 6.0$.

Immediately after collection, the samples were packed in a thermal box at room temperature and transported, within a maximum of one hour, to the Parasitology laboratory at the Federal University of Uberlândia where the analyses were carried out. 
The material for the Papanicolaou test, utilized as a comparative diagnostic methodology, was also collected during the gynaecological examination and sent to a third-party clinic which provides clinical services to the prison.

Vaginal samples analysis

\section{Wet mount}

The swab conserved in saline was homogenized and a drop of the sample was placed on a slide, covered with coverslip and observed, no later than two hours after the collection.

\section{Culture}

The tubes containing the swab and the culture medium were incubated at $37{ }^{\circ} \mathrm{C}$ for up to $96 \mathrm{~h}$. Every 24 hours a drop of the sample was placed on a slide, covered with coverslip and observed, to follow the development of the parasites.

A tube containing only culture medium was included in each round of incubation as a negative control.

\section{Microscopic analysis}

In order to provide a reliable diagnosis, samples of culture and wet mount were studied in triplicate, in an optic microscope (BX51, Olympus ${ }^{\mathrm{TM}}$ ) in bright field under the 40X objective by the same two specialists throughout the study. The specialists had access to the results of both tests, however they only received the results of the Papanicolaou test at the end of the study.

\section{Data collection instrument}

To delineate the socio-epidemiological profile of the inmates and to relate this to $T$. vaginalis infection, an investigative survey was performed with the participants at the time of the medical consultation. The patients were questioned about their age, ethnicity, marital status, sexual activity, smoking habits, contraceptive use, schooling, occupation, personal and sexual hygiene habits and socioeconomic situation. The complete survey is available as supplementary material (S1). 


\section{Ethical standards}

This study was approved by the Ethics Committee on Human Research of the Federal University of Uberlândia, under registration number 14009 .

\section{Statistical analysis}

Information was entered and analysed in the Epi Info version 3.5.1 database (CDC, Atlanta, GA, USA, 2008). For the comparison of two proportions, Fisher's Exact test was used. The OR with a 95\% confidence interval was established to quantify the association among potential risk factors for infection. Variables with $\mathrm{p}<0.05$ were considered significant for the infection. The sensitivity, specificity, positive and negative predictive values of the diagnostic methods were calculated using Bioestat 5.0 software (Belém, Pará, Brazil, Civil Society Mamirauá, 2007).

\section{RESULTS}

The complete profile of the participants in this study is described in Table 1. Of the total number of women analysed in this study $(\mathrm{n}=56)$ six $(10.7 \%)$ were positive for T. vaginalis, diagnosed, concomitantly, by culture, wet mount and Papanicolaou. The detailed results are shown in Table 2.

All positive women for $T$. vaginalis detected by culture $(n=7)$ were also diagnosed positive by wet mount. Apart from the six positive women, mentioned above, two others were positive exclusively by Papanicolaou and one, whose result had been positive for both culture and wet mount, had a negative Papanicolaou result.

Due to the high sensitivity and specificity of the culture method for $T$. vaginalis diagnosis all values of sensitivity, specificity, positive and negative predictive values of the other methods were calculated based on the results provided by this method.

Regarding the variables analysed in this study, none proved significant in relation to T. vaginalis infection. The social-epidemiological profile of the positive inmates and the risk factors associated with the disease are detailed in Table 3. 
Table 1. Socio-epidemiological profile of the female inmates at Jacy de Assis Prison in Uberlândia, Minas Gerais, Brazil

\begin{tabular}{|c|c|c|}
\hline Variable & $\mathrm{N}$ & $\%$ \\
\hline Age & $26 \pm 8.25^{\mathrm{a}}$ & \\
\hline \multicolumn{3}{|l|}{ Ethnicity } \\
\hline White & 22 & 39.3 \\
\hline Brown & 29 & 51.8 \\
\hline Black & 5 & 8.9 \\
\hline \multicolumn{3}{|l|}{ Marital status } \\
\hline Cohabitating & 27 & 48.2 \\
\hline Married & 6 & 10.7 \\
\hline Divorced & 3 & 5.4 \\
\hline Single & 20 & 35.7 \\
\hline \multicolumn{3}{|l|}{ Schooling } \\
\hline None & 1 & 1.8 \\
\hline 1 to 4 years & 8 & 14.3 \\
\hline 5 to 8 years & 34 & 60.7 \\
\hline 9 to 11 years & 2 & 3.6 \\
\hline More than 11 years & 11 & 19.6 \\
\hline \multicolumn{3}{|l|}{ Sexual preference } \\
\hline Heterosexual & 48 & 85.7 \\
\hline Bisexual & 8 & 14.3 \\
\hline Homosexual & 0 & 0 \\
\hline \multicolumn{3}{|l|}{ STI presence } \\
\hline Yes & 6 & 10.7 \\
\hline No & 50 & 89.3 \\
\hline \multicolumn{3}{|l|}{ Contraceptive methods } \\
\hline Condoms & 9 & 16 \\
\hline Other methods & 22 & 39.2 \\
\hline None & 25 & 44.7 \\
\hline \multicolumn{3}{|l|}{ Use of drugs } \\
\hline Yes & 41 & 73.2 \\
\hline No & 15 & 26.8 \\
\hline \multicolumn{3}{|l|}{ Sharing hygiene objects } \\
\hline Yes & 12 & 21.5 \\
\hline No & 44 & 78.5 \\
\hline \multicolumn{3}{|l|}{ Symptoms } \\
\hline Itching & 3 & 5.3 \\
\hline Pain in the womb/sexual relations & 6 & 10.8 \\
\hline Abnormal discharge & 6 & 10.7 \\
\hline None & 41 & 73.2 \\
\hline
\end{tabular}


Table 2. Results obtained by the culture, Papanicolaou and wet mount methods for the diagnosis of Trichomonas vaginalis in the 56 patients included in this study

\begin{tabular}{lcccccc}
\hline Method & $\begin{array}{c}\text { Positive } \\
(\%)\end{array}$ & $\begin{array}{c}\text { Negative } \\
(\%)\end{array}$ & $\begin{array}{c}\text { Sensitivity } \\
(\%)\end{array}$ & $\begin{array}{c}\text { Specificity } \\
(\%)\end{array}$ & $\begin{array}{c}\text { Positive } \\
\text { preditive } \\
\text { value } \\
(\%)\end{array}$ & $\begin{array}{c}\text { Negative } \\
\text { preditive } \\
\text { value } \\
(\%)\end{array}$ \\
\hline Culture & $7(12.5)$ & $49(87.5)$ & 100 & 100 & 100 & 100 \\
Papanicolaou & $8(14.3)$ & $48(85.7)$ & 75 & 96 & 68 & 98 \\
Wet mount & $7(12.5)$ & $49(87.5)$ & 100 & 100 & 100 & 100 \\
\hline
\end{tabular}

Table 3. Socio -epidemiological profile of the female inmates positive for T.vaginalis at Jacy de Assis Prison, Uberlândia, Minas Gerais and significance of the risk factors associated with the infection

\begin{tabular}{|c|c|c|c|c|c|c|}
\hline \multirow[t]{2}{*}{ Variable } & \multicolumn{2}{|c|}{ Positive } & \multicolumn{2}{|c|}{ Negative } & \multirow[t]{2}{*}{ p-value* } & \multirow[t]{2}{*}{ OR (CI) } \\
\hline & $\mathrm{N}$ & $\%$ & $\mathrm{~N}$ & $\%$ & & \\
\hline Age & \multicolumn{2}{|c|}{$26.5 \pm 11.5^{\mathrm{b}}$} & \multicolumn{2}{|c|}{$26.0 \pm 7.91^{\mathrm{b}}$} & 0.655 & \\
\hline Ethnicity & & & & & 0.386 & $0.27(0.30-2.54)$ \\
\hline White & 1 & 4.5 & 21 & 95.5 & & \\
\hline Brown/Black & 5 & 14.7 & 29 & 83.3 & & \\
\hline Marital status & & & & & 1.00 & $1.39(0.24-8.66)$ \\
\hline Cohabitating or married & 4 & 12.1 & 29 & 87.9 & & \\
\hline Divorced or single & 2 & 8.7 & 21 & 91.3 & & \\
\hline Schooling & & & & & 1.00 & $1.51(0.17-14.88)$ \\
\hline Up to 8 years & 5 & 11.6 & 38 & 88.4 & & \\
\hline More than 9 years & 1 & 7.7 & 12 & 92.3 & & \\
\hline Sexual preference & & & & & 0.200 & $0.272(0.04-1.82)$ \\
\hline Heterosexual & 4 & 8.3 & 44 & 91.7 & & \\
\hline Bisexual & 2 & 25.0 & 6 & 75.0 & & \\
\hline STI presence & & & & & 0.510 & $1.8(0.17-18.6)$ \\
\hline Yes & 1 & 16.7 & 5 & 83.3 & & \\
\hline No & 5 & 10.0 & 45 & 90.0 & & \\
\hline Contraceptive methods & & & & & 0.549 & $0.34(0.01-7.42)$ \\
\hline Pill & 0 & 0 & 8 & 100 & & \\
\hline Other methods & 3 & 13.0 & 20 & 87.0 & & \\
\hline Use of drugs & & & & & 0.172 & $5.67(0.30-107.2)$ \\
\hline Yes & 6 & 14.6 & 35 & 85.4 & & \\
\hline No & 0 & 0 & 15 & 100 & & \\
\hline Sharing hygiene objects & & & & & 0.574 & $0.03(0.01-6.50)$ \\
\hline Yes & 0 & 0 & 9 & 100 & & \\
\hline No & 6 & 12.8 & 41 & 87.2 & & \\
\hline Symptoms & & & & & 1.00 & $0.92(0.16-5.02)$ \\
\hline Yes & 3 & 10.3 & 26 & 89.7 & & \\
\hline No & 3 & 11.1 & 24 & 88.9 & & \\
\hline
\end{tabular}

${ }^{a}$ mean and standard deviation

* $\mathrm{p} \leq 0.05$ (Fisher's test); OR, odds ratio; CI, confidence interval: 95\%; sexually transmitted infections (STI). 


\section{DISCUSSION}

Infection rates of $T$. vaginalis vary greatly and this variation seems to be related, among other aspects, to the characteristics inherent to each population group (Kissinger, 2015). According to Freeman et al. (2010) and Petrin et al. (1998) some factors like age, sexual activity, number of partners, other STIs, menstrual cycle phase, diagnostic techniques, incarceration and socioeconomic conditions may influence the prevalence of the infection.

The prevalence of $T$. vaginalis $(10.7 \%)$ was corroborated by the data reported by Freeman et al. (2010) in a prison in San Francisco, California. However, Miranda et al. (2000), in the State of Espírito Santo, Brazil and Willers et al. (2008) in Rhode Island, United States found 30\% and 22\% prevalence, respectively, reinforcing the variation rates in the prevalence of this protozoan.

The average age of the positive inmates was 26.5 years, corresponding to the findings of Soper (2004) who claims that women in the 20 to 45 age group, seem to be more susceptible to infection by this parasite. This condition was also highlighted by Freeman et al. (2010), who noted a higher prevalence of $T$. vaginalis in women over 25 years of age.

According to Sutton et al. (2007) trichomoniasis highlights a remarkable health disparity, with black women showing infection rates up to ten times higher than white women. In this study, although ethnicity was not statistically significant, the proportion of infected brown/black women was five times higher than the proportion of infected white women. These data are in accordance with Evans et al. (1998) in England; Sorvillo et al. (2001), Scwebke \& Burguess (2004) and Miller et al. (2008) in the United States and Michel et al. (2006) in Brazil.

Our data indicated that the number of infected women was higher among married or cohabiting than among single or divorced women. These results were compatible with those presented by Michel et al. (2006). A possible explanation may be that the stability of the relationship discourages protective measures, either due to confidence or refusal by the partner (Silveira et al., 2002).

Although trichomoniasis often presents itself as a silent disease, in symptomatic women clinical manifestations such as vaginal irritation, abnormal vaginal odour, homogeneous discharge with leucorrhoea (this being purulent and gaseous), erythema in the vagina, pruritus and dysuria are noted. In this study, although half the positively diagnosed women showed symptoms, they could not be associated with the presence of the parasite.

Regarding the diagnostic methods tested, due to high levels of sensitivity and specificity of the culture method the patients who had the parasite identified in the vaginal sample by this technique were considered truly positive, and those whose material proved to be free of parasites at the 
end of the studt were truly negative. As all women considered positive by the wet mount were also positive by the culture method, $100 \%$ sensitivity and specificity for the wet mount method was reached, reinforcing the quality attributed by the literature to these methods.

On the other hand, Papanicolaou did not achieve equally high values in these criteria, confirming Soper (2004) who claims Papanicolaou is not a reliable diagnostic method. According to this same author, this test presents $50 \%$ sensitivity and $90 \%$ specificity. In addition, the predictive values for Papanicolaou reflected the lack of accuracy of the method, indicating a median probability of being ill when the result is positive $(60 \%)$ and a low probability of being ill when the result is negative (98\%).

Studies like this, with an epidemiological approach have some design limitations and although the prevalence rate obtained herein fits those reported in the literature, it was not possible to associate it with any risk factor, which may be partially explained by the size of the population, which might not be sufficiently large to highlight the effect. However, it should not be assumed that the results obtained herein are not valid.

Morbidity data by STIs in Brazilian prisons are rare and there are not enough reports describing the real situation in these places. Therefore, accurate diagnosis of trichomoniasis and precise identification of risk factors which predispose the infection is crucial for subsequent prevention and correct treatment, positively contributing to reduce infection rates. Further, it also improves life quality of the population in general and consequently reducing public expenditure on the disease itself and on its consequences. In this context, studies that include less subjective methods, such as NAAT and the comparison between larger and more heterogeneous prison populations can also provide valuable information.

The diagnosis of $T$. vaginalis by the culture method in TYM medium requires the use of an ATCC isolate as quality control of the methodology. However, due to financial limitations, this was not included in this study.

\section{CONFLICT OF INTEREST}

The authors hereby declare previous originality check, no conflict of interest and open access to the repository of data used in this paper for scientific purposes.

\section{ACKNOWLEDGMENTS}

The authors would like to thank the Administration of Jacy de Assis Penitentiary for enabling the present study and in particular to Dr Ana Paula Borges Vasconcelos for the sample collection. 


\section{REFERENCES}

1. Adad SJ, de Lima RV, Sawan ZT, Silva MLG, Souza MAH, Saladanha JC, Falco VAA, Cunha AH, Murta EFC. Frequency of Trichomonas vaginalis, Candida sp and Gardnerella vaginalis in cervical-vaginal smears in four different decades. Sao Paulo Med J 119: 200-205, 2001.

2. Adjei C, Boateng R, Dompreh A, Okyere B, Owiredu E. Prevalence and the evaluation of culture, wet mount, and ELISA methods for the diagnosis of Trichomonas vaginalis infection among Ghanaian women using urine and vaginal specimens. Trop Med Health 47: 33-41, 2019.

3. Bachmann LH, Hobbs MM, Seña AC, Sobel JD, Schwebke JR, Krieger JN, McClelland RS, Workowski KA. Trichomonas vaginalis genital infections: progress and challenges. Clin Infect Dis 53: 160-72, 2011.

4. Brasil. Departamento Penitenciário Nacional. Levantamento Nacional de Informações Penitenciárias. INFOPEN, 2018. 147p. Portuguese. Available in: < http://antigo.depen.gov.br/ DEPEN/depen/sisdepen/infopen> Accessed in: 02/2020

5. CDC. Center for Disease Control and Prevention. Sexually Transmitted Disease Treatment Guidelines. 55, 2006. Available in: <https://www.cdc.gov/std/tg2015/intro.htm> Accessed in: 02.2020

6. Davis DM, Bello JK, Rottnek F. Care of Incarcerated Patients. Am Fam Physician 98: 577-583, 2018.

7. Diamond LS. The stablishment of various trichomonads of animals and man in axenic cultures. J Parasitol 43: 488-490, 1957.

8. Evans BA, Kell PD, Bond RA, Macrae KD. Racial origin, sexual lifestyle, and genital infection among women attending a genitourinary medicine clinic in London 1992. Sex Transm Infect 74: 45-49, 1998.

9. Freeman AH, Katz KA, Pandori MW, Rauch LM, Kohn RP, Liska S, Bernstein KT, Klausner JD. Prevalence and correlates of Trichomonas vaginalis among incarcerated persons assessed using a highly sensitive molecular assay. Sex Transm Dis 37: 165-168, 2010.

10. Hardick A, Hardick J, Wood BJ, Gaydos C. Comparison between the Gen-Probe transcriptionmediated amplification Trichomonas vaginalis research assay and real-time PCR for Trichomonas vaginalis detection using a Roche LightCycler instrument with female selfobtained vaginal swab samples and male urine samples. J Clin Biol 44: 4197-4199, 2006.

11. Kissinger P. Trichomonas vaginalis: a review of epidemiologic, clinical and treatment issues. BMC Infect Dis 15: 307-315, 2015.

12. Michel RV, Borges FP, Wiltuschnig RC, Neves FG, Ribeiro J, Vieiro RC, Vieira P, Bohns G, Tasca T, Carli GA. Prevalência da Tricomonose em mulheres residentes na Vila dos Papeleiros em Porto Alegre, RS. Rev Bras Anal Clinic 38: 127-130, 2006.

13. Miller M, Liao Y, Gomez AM, Gaydos CA, D'Mellow D. Factors associated with the prevalence and incidence of Trichomonas vaginalis infection among African American women in New York City who use drugs. J Infect Dis 197: 503-509, 2008.

14. Miranda AE, Vargas PM, St Louis ME, Viana MC. Sexually transmitted diseases among female prisioners in Brazil: prevalence and risk factors. Sex Transm Dis 27: 491-495, 2000.

15. Perl G. Errors in the diagnosis of Trichomonas vaginalis infections as observed among 1,199 patients. Obstet Gynecol 39: 7-9, 1972.

16. Petrin D, Delgaty K, Bhatt R, Garber G. Clinical and microbiological aspects of Trichomonas vaginalis. Clin Microbiol Rev 11: 300-317, 1998.

17. Poole DN, McClelland RS. Global epidemiology of Trichomonas vaginalis. Sex Transm Infect 89: 418-422, 2013. 
18. Rowley J, Vander Hoorn S, Korenromp E, Low N, Unemo M, Abu-Raddad LJ, Chico RM, Smolak A, Newman L, Gottlieb S, Thwin SS, Broutet N, Taylor MM. Chlamydia, gonorrhoea, trichomoniasis and syphilis: global prevalence and incidence estimates. Bull World Health Organ. 97: 548-562, 2019

19. Schwebke JR, Burgess D. Trichomoniasis. Clin Microbiol Rev 4: 794-803, 2004.

20. Shuter J, Bell D, Graham D, Hollbrook KA, Bellin EY. Rates of and risk factors for trichomoniasis among pregnant inmates in New York City. Sex Transm Dis 25: 303-307, 1998.

21. Silveira MF, Beria JU, Horta BL, Tomasi E, Victora CG. Factors associated with risk behaviors for sexually transmitted disease/AIDS among urban Brazilian women: a population-based study. Sex Transm Dis 29: 536-541, 2002.

22. Silver BJ, Guy RJ, Kaldor JM, Jamil MS, Rumbold AR. Trichomonas vaginalis as a cause of perinatal morbidity: a systematic review and meta-analysis. Sex Transm Dis 41: 369-376, 2014.

23. Soper D. Trichomoniasis: under control or undercontrolled? Am J Obstet Gynecol 190: 281290, 2004.

24. Sorvillo F, Smith L, Kerndt P, Ash L. Trichomonas vaginalis, HIV and African-Americans. Emerg Infect Dis 7: 927-932, 2001.

25. Sutton M, Sternberg M, Koumans EH, McQuillan G, Berman S, Markowitz L. The prevalence of Trichomonas vaginalis infection among reproductive-age women in the United States, 2001-2004. Clin Infect Dis 45: 1319-1326, 2007.

26. Van Der Pol B. Trichomonas vaginalis infection: the most prevalent nonviral sexually transmitted infection receives the least public health attention. Clin Infect Dis 44: 23-25, 2007.

27. Vlahov D, Brewer F, Muñoz A, Hall D, Taylor E, Polk BF. Temporal trends of human immunodeficiency virus type 1 (HIV-1) infection among inmates entering a statewide prison system, 1985-1987. JAIDS 2: 283-290, 1989.

28. Willers DM, Peipert JF, Allsworth JE, Stein MD, Rose JS, Clarke JG. Prevalence and predictors of sexually transmitted infection among newly incarcerated females. Sex Transm Dis 35: 68$72,2008$.

29. World Health Organization (WHO). Sexually Tansmitted Infections (STIs). Geneva, Switzerland, 2016. Available in: $<$ https://www.who.int/news-room/fact-sheets/detail/sexuallytransmitted-infections-(stis) $>$ Accessed in: 02/2020

30. World Health Organization (WHO). Report on global sexually transmitted infection surveillance, 2018. Geneva, Switzerland, 2018. Available in: <https://www.who.int/ reproductivehealth/publications/stis-surveillance-2018/en/> Accessed in: 02.2020

31. Workowski KA, Bolan GA. Sexually transmitted diseases treatment guidelines, 2015. MMWR. Recommendations and reports:Morbidity and mortality weekly report. CDC Home 64: 1-137, 2015. 